05

\title{
Ударопрочные керамические материалы на основе карбида кремния
}

\author{
(C) С.Н. Перевислов ${ }^{1}$, И.А. Беспалов ${ }^{2}$ \\ ${ }^{1}$ Санкт-Петербургский государственный технологический институт \\ (Технический университет) \\ ${ }^{2}$ Научно-исследовательский институт стали, Москва \\ E-mail: perevislov@mail.ru
}

Поступило в Редакцию 1 ноября 2016 г.

Определена пулестойкость косвенным методом, путем оценки времени задержки проникновения пули в керамику на основе карбида кремния, полученную реакционным, жидкофазным спеканием и горячим прессованием.

DOI: $10.21883 /$ PJTF.2017.15.44873.16552

Высокотвердые материалы, такие как керамика, более эффективны в качестве защиты против воздействия пуль с термоупрочненным стальным сердечником, чем другие материалы (в частности, металлы). По сравнению с другими видами керамик карбид кремния обладает уникальными свойствами: высокими твердостью и модулем упругости, а также низкой плотностью (в 2.5 раза ниже плотности стали) [1].

Скорость прохождения ударной волны в бронематериале зависит от его плотности и модуля упругости. Твердость важна при определении исходного разрушения пули. Высокая скорость распространения ударной волны позволяет рассеивать кинетическую энергию пули. Важными свойствами керамических материалов, определяющими качество брони и влияющими на степень ее пулестойкости, являются коэффициент трещиностойкости и прочность при изгибе [2].

Броневые материалы на основе карбида кремния получают горячим прессованием, реакционным и жидкофазным спеканием и др. Метод спекания в 3-5 раз дешевле горячего прессования, однако получать крупногабаритные броневые плиты размером более $200 \times 200 \mathrm{~mm}$ путем свободного спекания достаточно сложно [3].

Реакционно-спеченный (самосвязанный) карбид кремния ( $\mathrm{SiSiC}$ ) широко распространен в промышленности благодаря практически 
Таблица 1. Составы образцов, исследуемых в работе

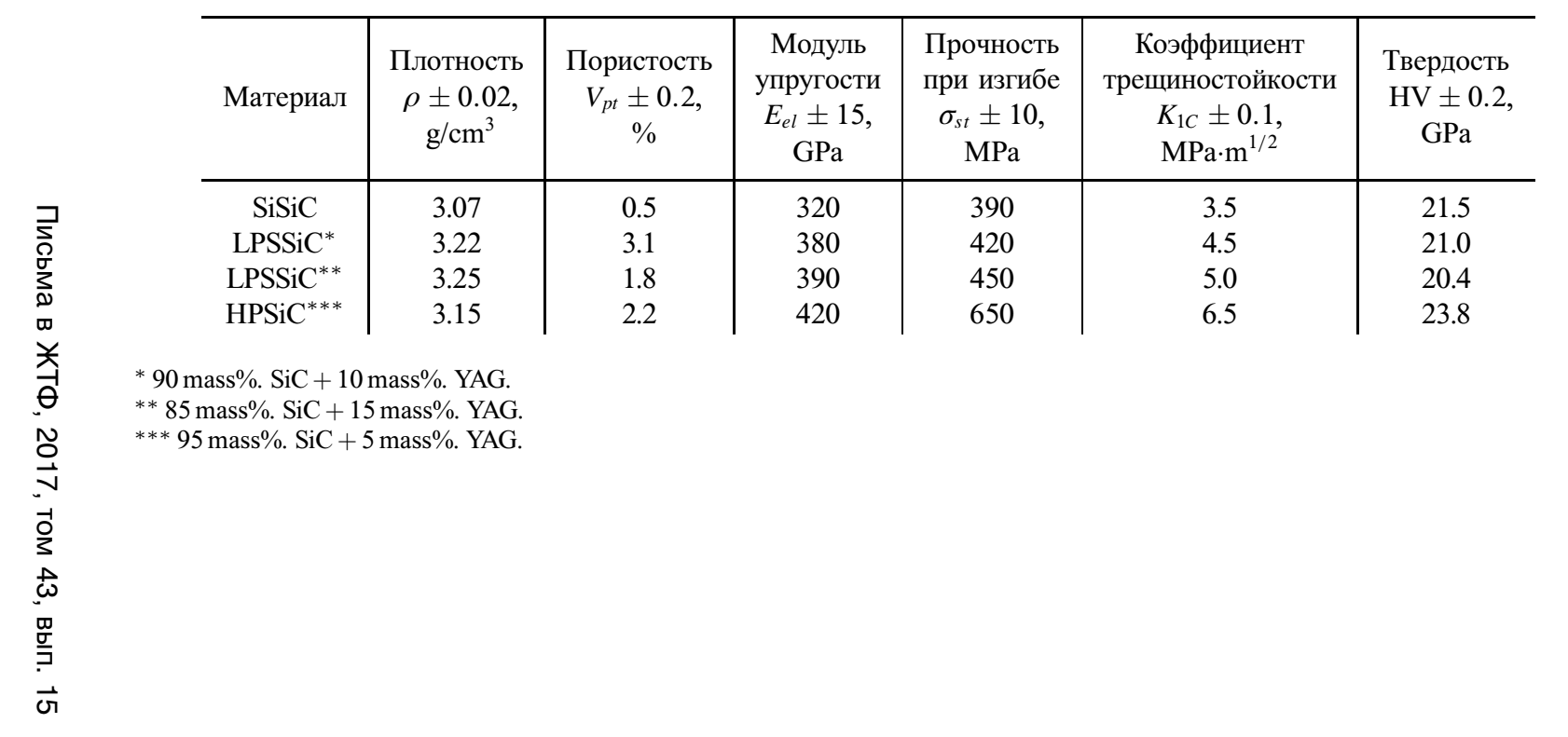


безусадочной технологии и низкой температуре спекания. SiSiCматериалы получают пропиткой жидким кремнием пористых заготовок, включающих первичный карбид кремния $\left(\mathrm{SiC}^{\mathrm{I}}\right)$ и углерод, за счет образования на поверхности первичных частиц вторичного карбида $\left(\mathrm{SiC}^{\mathrm{II}}\right)$. Этот метод приводит к получению плотных композитов $\mathrm{SiC} / \mathrm{SiC}$ при температуре $\geq 1600^{\circ} \mathrm{C}[4]$, обладающих повышенной хрупкостью, что снижает его пулестойкость. Свойства SiSiC-материалов представлены в табл. 1.

Перспективным материалом, спекающимся до высокой относительной плотности $\left(\rho_{r} \geq 98 \%\right)$, является жидкофазно-спеченный карбид кремния (LPSSiC). Его главными преимуществами по сравнению с горячепрессованными материалами являются возможность получения материалов сложной геометрической формы в широком диапазоне размеров и их высокая производительность. К недостаткам материалов можно отнести значительную усадку при спекании [5]. Спеченный материал характеризуется наличием зерен $\mathrm{SiC}$, связанных оксидной фазой. Уровень механических свойств LPSSiC выше такового для SiSiCматериалов (табл. 1).

Горячепрессованные $\mathrm{SiC}$-материалы (HPSiC) получают спеканием мелкодисперсного $\mathrm{SiC}$-порошка с 3-5 mass\% оксидных добавок при температуре $1700-1800^{\circ} \mathrm{C}$ [5]. В процессе горячего прессования формируется монолитный, низкопористый материал с высоким уровнем механических свойств (табл. 1). Однако большая энергоемкость и низкая производительность ограничивают получение изделий HPSiC в промышленном масштабе.

Полученные материалы обладают низкой пористостью, что определяет высокий уровень $K_{1 C}$ и HV. Коэффициент трещиностойкости материала зависит от прочности межзеренного сцепления на границе фаз. По сравнению с $\mathrm{SiSiC-материалами} \mathrm{коэффициент} \mathrm{трещиностойко-}$ сти которых определяется слабой прочностью на границах раздела фаз $\mathrm{SiC}^{\mathrm{I}}-\mathrm{SiC}^{\mathrm{II}}$ и $\mathrm{SiC}^{\mathrm{I}}-\mathrm{Si}-K_{1 C}=3.5 \pm 0.1 \mathrm{MPa} \cdot \mathrm{m}^{1 / 2}[6]$, коэффициент трещиностойкости LPSSiC-материалов выше $-K_{1 C}=5.0 \pm 0.1 \mathrm{MPa} \cdot \mathrm{m}^{1 / 2}$ (с добавкой 15 mass\%. YAG) (табл. 1).

Твердость керамических материалов зависит от твердости входящих в их состав фаз и при увеличении содержания оксидов как менее твердых компонентов уровень HV снижается (табл. 1).

Максимальный уровень свойств достигается на HPSiC- и LPSSiC-материалах (при 15 mass\% YAG). Повышению свойств $\mathrm{SiSiC}$

Письма в ЖТФ, 2017, том 43, вып. 15 
могут способствовать введение в состав материала волокон $\mathrm{C}_{f}$ и $\mathrm{SiC}_{f}$ и регулирование зернового состава исходных компонентов, размера и конфигурации пор, количества кремния.

Разрушение исследуемых материалов идет преимущественно по интеркристаллитному механизму, трещина распространяется по межзеренной связке, огибая зерна $\mathrm{SiC}$.

Испытания на пулестойкость керамических материалов проводили путем определения времени задержки проникания высокоскоростных ударников в керамическую броню [7] в РЦИ СИЗ ОАО „НИИ стали“. Принцип метода основан на предположении, что величина, на которую укорачивается сердечник пули при пробитии свободно подвешенной керамической пластины, определяется временем задержки проникновения в керамику $\left(t_{p}\right)$

$$
l_{\text {init }}-l_{\text {res }}=v_{0} \cdot t_{p}
$$

где $l_{\text {init }}$ - начальная длина сердечника пули, равная $28.5 \mathrm{~mm}, l_{\text {res }}$ остаточная длина сердечника после пробития преграды, $v_{0}$ - начальная скорость пули.

Время задержки проникания ударника в керамику определяется как видом и свойствами керамики, так и свойствами ударника, а именно плотностью, твердостью, формой и скоростью пули. Поэтому если проводить испытания керамических пластин в одинаковых условиях (один вид керамики и равный выбранный перечень свойств ударника), то время задержки проникания ударника в керамику условно можно считать показателем „броневых“ свойств материала. Наиболее подходящей в качестве стандартного ударника оказалась бронебойнозажигательная пуля Б-32 калибра $7.62 \mathrm{~mm}$, имеющая максимальные характеристики: твердость и плотность. Штатная скорость пули, выпущенной из снайперской винтовки Драгунова, на расстоянии $5 \mathrm{~m}$ от дульного среза составляет $818 \pm 17 \mathrm{~m} / \mathrm{s}$.

Поскольку в процессе распространения по керамическому слою ударные волны быстро затухают, предполагается, что для достижения достаточного для разрушения уровня растягивающих напряжений и времени их действия требуется несколько волновых пробегов по слою керамики

$$
t_{p}=n_{p r} \frac{h_{c}}{c_{c}},
$$

где $h_{c}$ - толщина керамики, $c_{c}$ - скорость звука в керамике, $n_{p r}-$ число волновых пробегов, необходимое для разрушения (безразмерное время задержки проникания ударника в керамику) [8].

Письма в ЖТФ, 2017, том 43, вып. 15 


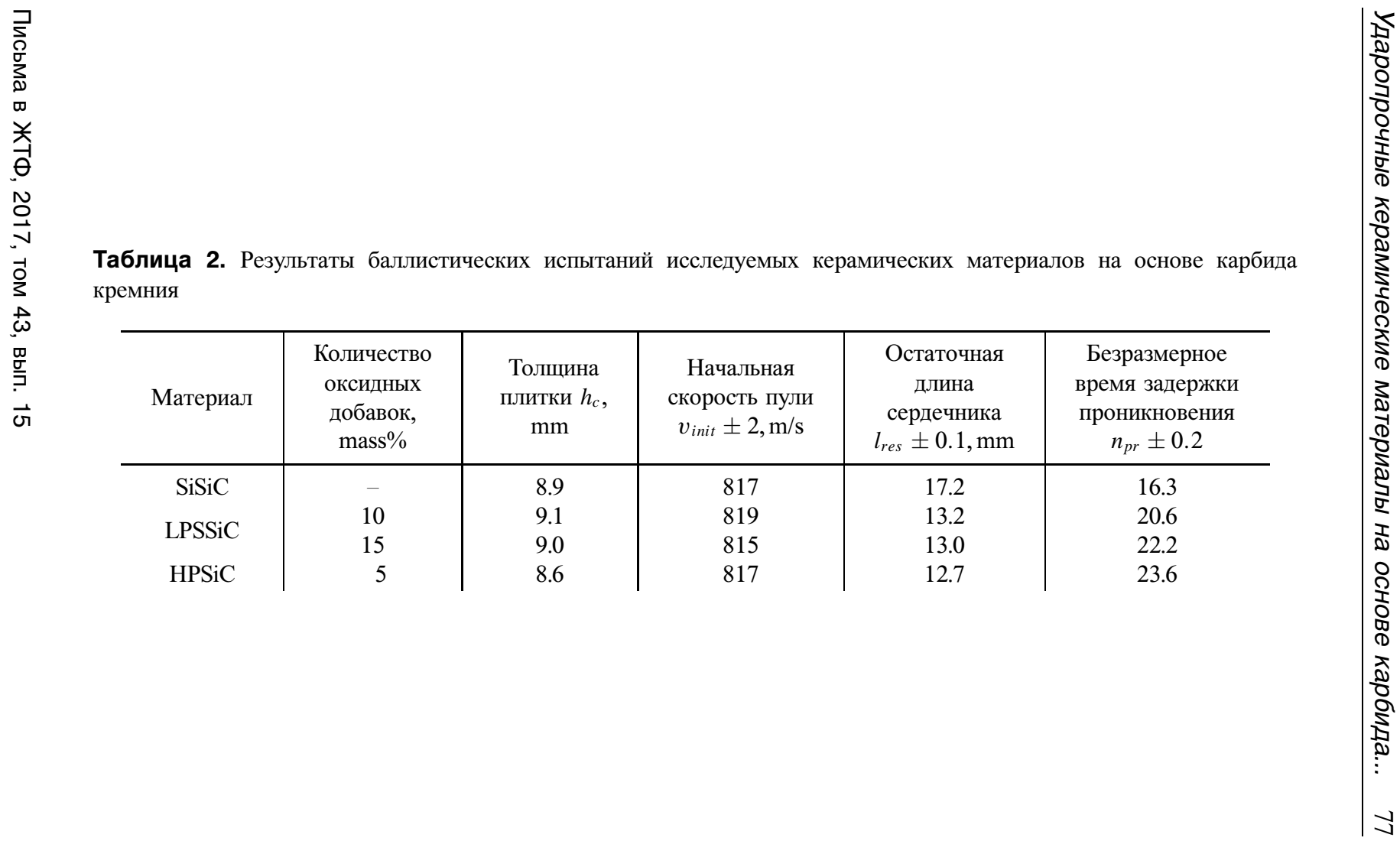


Для освобождения от геометрического параметра (толщины керамического слоя) принимаем за показатель качества керамики $n_{p r}$. При определении $n_{p r}$ толщину пластины относили к некоторой постоянной скорости звука (для карбида кремния $c_{c}=10.5 \mathrm{~km} / \mathrm{s}$ ):

$$
n_{p r}=t_{p} \frac{c_{c}}{h_{c}} .
$$

В табл. 2 приведены результаты испытаний пулестойкости керамики (по 3 плитки каждого состава).

Высокий уровень механических свойств HPSiC-материалов определяет их значительную пулестойкость. Показатель $n_{p r}$ LPSSiC (15 mass\% YAG) составляет $22.2 \pm 0.2$ (табл. 2) и приближается к уровню $n_{p r}$ HPSiC-материала. Для повышения значения $n_{p r}$ SiSiC-керамики целесообразно в состав материала вводить армирующие компоненты (волокна $\mathrm{C}_{f}$ и $\mathrm{SiC}_{f}$ ), повышающие уровень механических свойств и, вероятнее всего, пулестойкость.

Косвенный метод определения пулестойкости керамики путем определения времени задержки проникновения пули хорошо согласуется с результатами измерения бронестойкости панелей, содержащих керамические плитки на основе $\mathrm{SiC}$, по ГОСТ 50744-95 и может быть использован при оценке качества единичных керамических элементов.

\section{Список литературы}

[1] Анастасиади Г.П., Сильников М.В. Работоспособность броневых материалов. СПб.: Астерион, 2004. 624 с.

[2] Каннель Г.И., Разоренов С.В., Уткин А.В. и др. Ударно-волновое явление в конденсированных средах. М.: Изд-во „Янус-К“, 1996. 408 с.

[3] Briggs J. Engineering ceramics in Europe and the USA. UK-Worcester, 2011. $331 \mathrm{p}$.

[4] Yanxiang B., ShouHong T., Dongliang J. // Ceramics International. 2004. V. 30(3). P. 435-439.

[5] Перевислов С.Н., Несмелов Д.Д. // Огнеуп. и техн. керамика. 2014. № 4/5. C. 3-13.

[6] Синани А.Б., Кожушко А.А., Зильбербранд Е.Л. // Письма в ЖТФ. 2008. T. 34(3). C. 27-31.

[7] Беспалов И.А., Григорян В.А., Кобылкин И.Ф. // Вопросы оборонной техники. Серия 15-Композиц. неметаллич. материалы в машиностроении. 2011. № 1-2. C. 34-38.

[8] Григорян B.A. и др. Материалы и защитные структуры для локального и индивидуального бронирования. М.: Радиософт, 2008. 406 с. 